\title{
Turning $\mathrm{CO}_{2}$ Capture $\mathrm{On}$ and $\mathrm{Off}$ in Response to Electric Grid Demand: A Baseline Analysis of Emissions and Economics
}

\author{
Stuart M. Cohen \\ Department of Mechanical Engineering, \\ University of Texas at Austin, \\ Austin, TX 78712 \\ e-mail: stuart.cohen@mail.utexas.edu
}

Gary T. Rochelle
Department of Chemical Engineering,
University of Texas at Austin,
Austin, TX 78712
e-mail: gtr@che.utexas.edu
Michael E. Webber
Department of Mechanical Engineering,
University of Texas at Austin,
Austin, TX 78712
e-mail: webber@mail.utexas.edu

1 Introduction

There is a consensus among scientists that climate change is occurring primarily due to carbon dioxide $\left(\mathrm{CO}_{2}\right)$ emissions from fossil fuel burning, with over $60 \%$ of worldwide emissions coming from power generation systems [1]. Coal-fired power plants account for $60 \%$ of electricity sector emissions, 11.4 billion metric tons of $\mathrm{CO}_{2}$ emitted in 2005, and 2.1 billion in the U.S [2,1]. However, when compared with other fuels used for electricity production, coal is relatively inexpensive, abundant, and politically secure. This advantageous combination indicates that the use of coal for power generation may increase in the coming decades, despite its $\mathrm{CO}_{2}$ output. In order to continue and expand coal use in an environmentally acceptable manner, it will be essential to implement carbon dioxide capture and sequestration (CCS) systems.

Major barriers to CCS technology are its high capital cost and operating costs associated with the energy requirement of capture

Contributed by the Advanced Energy Systems Division of ASME for publication in the Journal of Energy Resources Technology. Manuscript received March 1, 2009; final manuscript received March 29, 2010; published online May 17, 2010. Assoc. Editor: B. G. Shiva Prasad. systems, which can significantly lower overall power plant thermal efficiency. For a plant using post-combustion (PC) amine absorption, one leading technology, the net output can be $11-40 \%$ lower than an equivalent reference plant without $\mathrm{CO}_{2}$ capture $[1,3,4]$. A primary portion of this energy requirement is the steam required to heat $\mathrm{CO}_{2}$-rich solvent to an appropriate temperature where the $\mathrm{CO}_{2}$ can be liberated for subsequent transport and storage (Fig. 1). In a typical design, steam is diverted from between the intermediate- and low-pressure turbines and directed to a stripper column where the $\mathrm{CO}_{2}$-rich solvent flows in for regeneration. The other major $\mathrm{CO}_{2}$ capture energy requirement is the work needed to compress $\mathrm{CO}_{2}$ to pipeline pressure. The $\mathrm{CO}_{2}$ compression train could be driven by an electric motor or by expanding the stripping steam in a let-down steam turbine before it reaches the stripper column.

Several techno-economic analyses of $\mathrm{CO}_{2}$ capture systems exist in the literature, but most take either the bottom-up approach of a single plant analysis or employ a top-down macroeconomic methodology $[5,6]$. Plant-level studies are necessary to identify detailed plant tradeoffs between performance, economics, and environmental effects, but they typically have limited ability to analyze the implications of dynamic plant operation within the framework of the electric grid. Macroscopic energy analyses are 


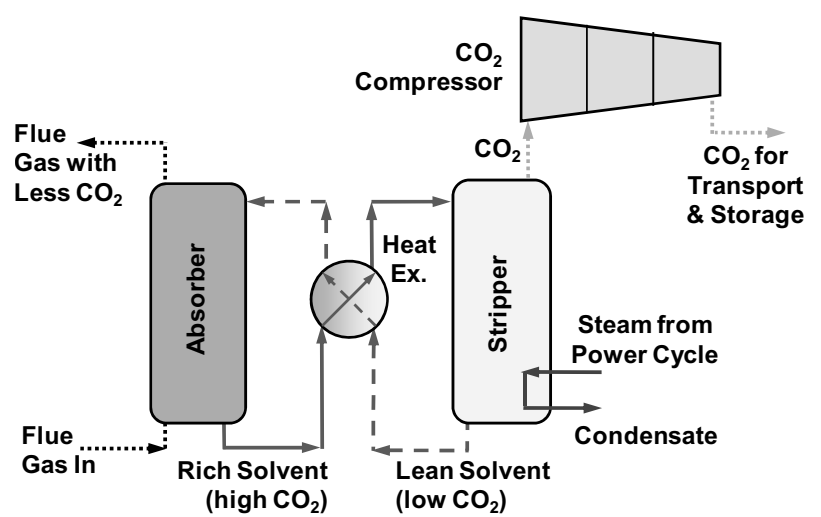

Fig. 1 A Process diagram shows the key features of a typical $\mathrm{CO}_{2}$ absorption/stripping unit with $\mathrm{CO}_{2}$ compression

useful for understanding long-term drivers of energy use, but they too have limited capability to capture the short-term implications of dynamic electricity supply and demand.

This study takes an intermediate approach of an electric gridlevel perspective in order to make baseline estimates of the implications of turning $\mathrm{CO}_{2}$ capture systems on and off in response to electric grid demand. While prior analysis investigates plant-level options and implications of flexible $\mathrm{CO}_{2}$ capture, this study seeks to better understand the effects of on/off operation at a system level [7]. Flexible $\mathrm{CO}_{2}$ capture operation is particularly suited for PC $\mathrm{CO}_{2}$ capture systems, which may be designed to allow for the possibility of recovering the energy required for $\mathrm{CO}_{2}$ capture when it is desirable to increase plant output. PC capture systems can also be more easily retrofitted to current plants, offering a level of flexibility to the electric grid itself. Because of the large body of knowledge surrounding monoethanolamine (MEA) based $\mathrm{CO}_{2}$ capture systems, $\mathrm{PC} \mathrm{CO}_{2}$ capture using an aqueous MEA solution is considered exclusively in this report.

Turning $\mathrm{CO}_{2}$ capture "off" does not necessarily refer to bringing all systems associated with $\mathrm{CO}_{2}$ capture to a full halt, as this practice may be undesirable from an equipment operation and maintenance perspective. In the context of this study, an off configuration refers to the recovery of plant capacity to its base rating without $\mathrm{CO}_{2}$ capture installed. Full capacity is achieved by redirecting solvent regeneration steam back to the low-pressure turbine where it can be used to generate electricity. In a configuration with sufficient solvent storage, it may be possible to continue to capture $\mathrm{CO}_{2}$ and hold $\mathrm{CO}_{2}$-rich solvent in storage tanks for regeneration during periods of lower electricity demand, but a worstcase environmental scenario would assume that $\mathrm{CO}_{2}$ is vented in a "capture off" configuration. An on/off operation with $\mathrm{CO}_{2}$ venting can be pictured as a system that cycles between its full-load (on) and zero-load (off) operating points, where maximum specified $\mathrm{CO}_{2}$ removal is achieved at full-load, and no $\mathrm{CO}_{2}$ is removed from flue gas at zero-load. As has been identified in prior work, turning off energy intensive $\mathrm{CO}_{2}$ capture systems during periods of peak electricity demand can eliminate the need for investment in new generation capacity to replace that lost from $\mathrm{CO}_{2}$ capture energy requirements [8]. If the system response time is short enough, the on/off operation may provide a useful tool for plant operators to better match plant generation with diurnal electricity demand variation. The ability to turn $\mathrm{CO}_{2}$ capture systems off at the times of the day when electricity is most expensive also offers the opportunity for faster recovery of CCS investment costs relative to a case when $\mathrm{CO}_{2}$ capture operates continuously at its fullload.

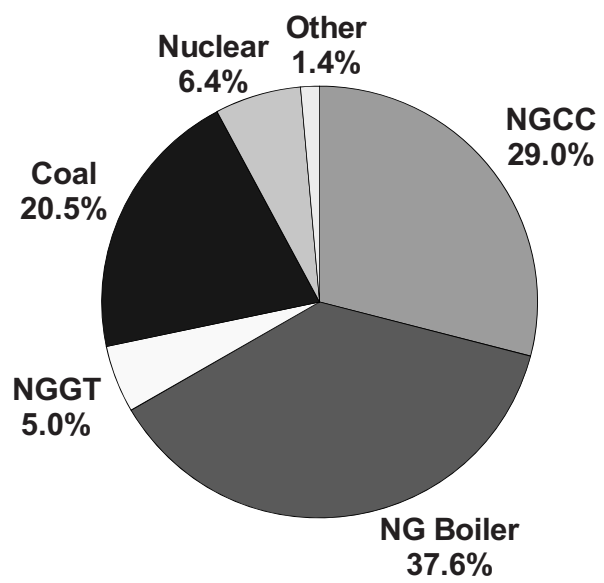

Fig. 22006 ERCOT installed capacity of each plant type is shown, demonstrating dominance of natural gas $[9,21]$

\section{Methodology}

The purpose of this study is to analyze strategies for on/off $\mathrm{CO}_{2}$ capture in order to determine baseline estimates of the tradeoffs between power generation performance, economics, and $\mathrm{CO}_{2}$ emissions. Rather than attempt to optimize on/off operation for specific goals such as minimum cost under a $\mathrm{CO}_{2}$ emissions limit, the goal of this study is to offer insight into grid-level implications of several on/off $\mathrm{CO}_{2}$ capture scenarios to better understand how flexible $\mathrm{CO}_{2}$ capture might affect a widespread deployment of CCS

2.1 A Case Study of ERCOT Electric Grid. The Electric Reliability Council of Texas (ERCOT) electric grid is examined using grid specifications and performance from the year 2006. This year is chosen because of the completeness of publicly available data from ERCOT and U.S. government agencies. ERCOT is responsible for managing the retail electricity market that accounts for $85 \%$ of the total electricity generation in Texas [9]. In 2006, the ERCOT installed capacity was 71,812 MW, and Fig. 2 shows how this capacity is broken down by source [9]. Unlike rated capacity, which indicates the maximum power that could be produced if all generators were online and operating at their optimum conditions, installed capacity shown in Fig. 2 accounts for the expected annual availability of each generation source. NGCC refers to natural gas-powered combined cycle generation, NG boilers are steam cycle power plants using natural gas-fired boilers, and NGGT are open cycle gas turbine-driven generators. For the purposes of this analysis, wind, hydroelectric, and other plant types are lumped into a single "other" category because they comprise a relatively small portion of the generation mix. Because $75 \%$ of the actual generation within this category came from wind in 2006, parameters associated with the "other" generation correspond to appropriate values for wind power.

In the ERCOT grid, coal-based and nuclear power operate at a relatively constant output for base load capacity, while natural gas is used both to meet additional base load demand and to balance electricity supply and demand by serving intermediate and peaking load. Thus, higher capacity factors allow coal-fired and nuclear plants to account for $37.4 \%$ and $13.6 \%$ of the total ERCOT generation in 2006. Lower capacity factor natural gas-fired plants produced $46.3 \%$ of the ERCOT electricity in 2006 [10]. Figure 3, taken from a 2005 ERCOT resource update, illustrates the current ERCOT operational strategy for the day in 2005 when electricity demand was at its maximum.

ERCOT uses a reserve margin specification as an important metric to decide whether or not new capacity is required to maintain grid reliability. The reserve margin is defined as the percent of installed capacity that is available during the maximum peak elec- 


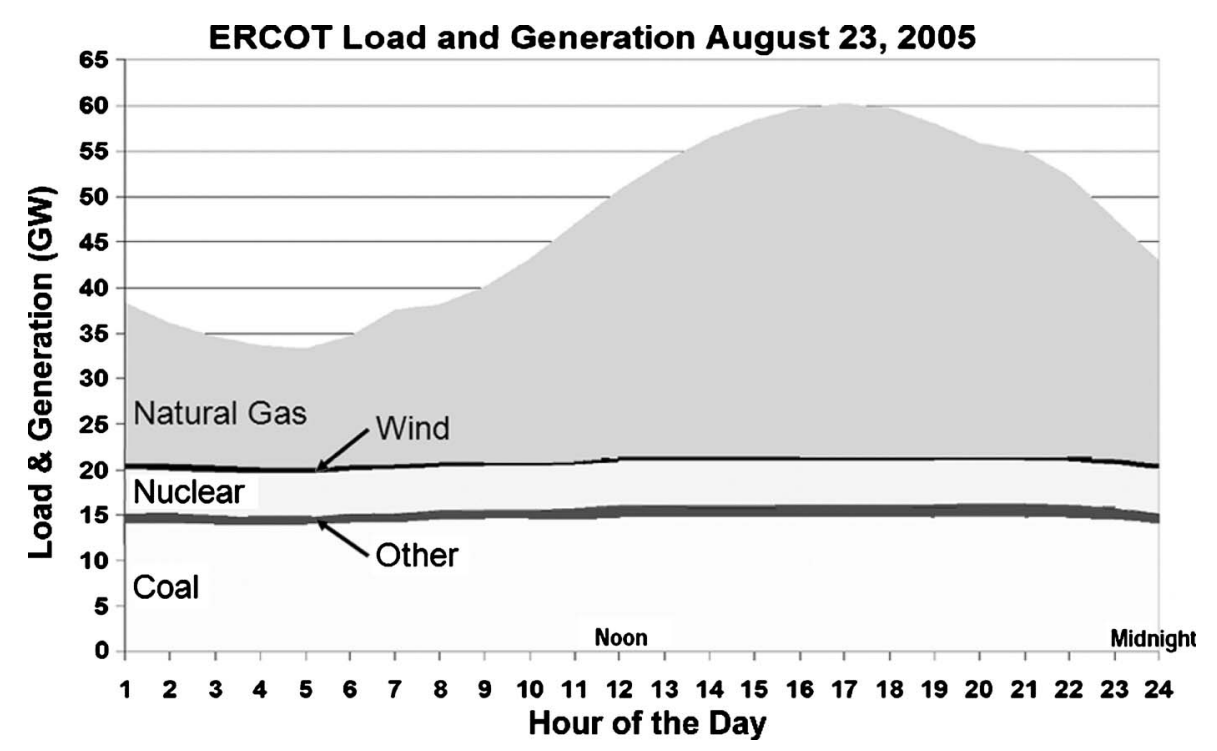

Fig. 3 ERCOT load and generation by plant type on August 23, 2005 demonstrates dependence on natural gas on the maximum peak load day in 2005 [10]

tricity load of the year. ERCOT specifies that it must maintain a $12.5 \%$ reserve margin; thus, new capacity installation becomes important when the observed reserve margin approaches this value. The 2006 ERCOT observed reserve margin in 2006 was $14.6 \%$. The projected growth in electricity demand indicates that new capacity will likely be necessary to maintain ERCOT reliability regardless of $\mathrm{CO}_{2}$ capture installation.

2.2 General Model Assumptions. A matLab model is created to compare performance, economics, and emissions of several scenarios. Historical ERCOT hourly load data are taken as inputs, and a decision tree for each scenario determines how much of that load is met by each generation source. Because the lowest ERCOT demand in 2006 never dropped below combined coalbased and nuclear capacity, coal-fired and nuclear facilities are assumed to always run at full capacity. Wind and hydroelectric power are intermittent in reality, but because of their relatively small overall contribution to ERCOT generation in 2006, power output from the "other" category is taken as a constant average value throughout the year. Because different gas-fired generation types vary significantly in efficiency, and by extension, electricity production costs, NGCC, NG boilers, and NGGT are considered separately. The model utilizes natural gas-fired plant types in the order of lowest to highest generation cost, which is calculated, as described in Sec. 2.4.4 below.

Scenarios that implement $\mathrm{CO}_{2}$ capture consider the operation of the above generation mix if $\mathrm{PC} \mathrm{CO}_{2}$ capture using MEA is installed on all 15 coal-fired power plants in the ERCOT grid. When fully on, the model assumes that $\mathrm{CO}_{2}$ capture reduces coal-fired generation capacity by a specified percent and captures $90 \%$ of plant $\mathrm{CO}_{2}$ emissions, an often cited $\mathrm{CO}_{2}$ capture efficiency $[1,3,5]$. Turning $\mathrm{CO}_{2}$ capture off allows full recovery of the original plant output and generation cost, and $\mathrm{CO}_{2}$ is assumed vented to the atmosphere in an off configuration. An actual retrofitted plant incorporating on/off $\mathrm{CO}_{2}$ capture may not regain its base performance with the $\mathrm{CO}_{2}$ capture off, but the effect of such a residual energy penalty is not considered in this baseline study.

$\mathrm{PC} \mathrm{CO}$ capture for natural gas-fired plants is not considered in this study. While such systems are technically feasible and would further reduce emissions, the lower emission rates of natural gasbased plants relative to coal-fired facilities mean that a greater volume of flue gas must be treated to capture a given amount of $\mathrm{CO}_{2}$. Since the resulting energy requirement and cost per amount of $\mathrm{CO}_{2}$ avoided is likely to be greater, this option is not included in the model [11].

In practice, the amount of the total installed capacity available for generation varies throughout the year due to factors such as planned maintenance outages, forced outages due to unexpected equipment failures, and discrepancies between design and actual operating conditions. Because much of this variation depends on system planning and unplanned events, and because these events are considered when specifying a reserve margin, predicting and accounting for variation in available capacity is considered to be outside the scope of this study.

2.3 Scenario Descriptions. The specific scenarios analyzed are described below.

2.3.1 BAU: Business as Usual, No $\mathrm{CO}_{2}$ Capture. This case describes the actual 2006 ERCOT configuration, where no power plants utilize $\mathrm{CO}_{2}$ capture (status quo).

2.3.2 CCS Base: Inflexible $\mathrm{CO}_{2}$ Capture. $\mathrm{CO}_{2}$ capture operates continuously throughout the year, decreasing the total coalfired generation capacity by a constant amount. This scenario represents the system configuration in studies that do not consider $\mathrm{CO}_{2}$ capture flexibility [4,5]. Depending on an ERCOT reserve margin specification or an otherwise defined threshold electricity demand, new generation capacity may be required in this scenario. Because $\mathrm{CO}_{2}$ capture reduces base load coal-fired generation capacity, this scenario assumes that any new capacity consists of coal-based power generation with $\mathrm{CO}_{2}$ capture installed. New capacity planning decisions are based on a variety of technical, economic, and political influences, but the above methodology allows for a more direct comparison with studies that assume that the energy requirement of $\mathrm{CO}_{2}$ capture requires building an equivalent facility with greater gross power output.

2.3.3 FLEX Daily: Flexible $\mathrm{CO}_{2}$ Capture Option. $\mathrm{CO}_{2}$ capture is turned off every day of the year when demand exceeds the daily peak minus $\mathrm{CO}_{2}$ capture energy requirements. Thus, $\mathrm{CO}_{2}$ capture is turned off for some amount of time everyday, regardless of the magnitude of the daily peak. This operational strategy may not be realistic due to additional $\mathrm{CO}_{2}$ emissions and increased capital recovery time, but it represents a worst-case environmental scenario for flexible $\mathrm{CO}_{2}$ capture in the event that economics dictate a much more limited use of the "capture on" configuration. Figure 


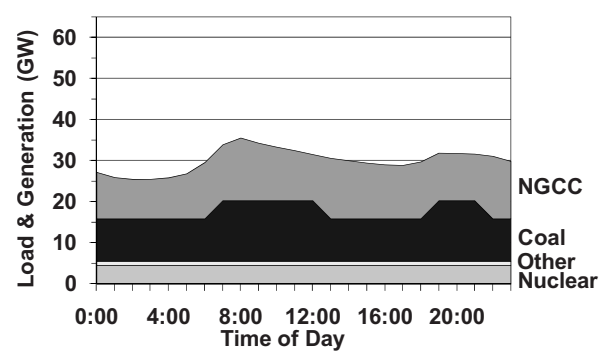

Fig. 4 The FLEX Daily load and generation on January 6, 2006 has two $\mathrm{CO}_{2}$ capture off periods when load nears daily peak load

4 displays how this strategy would utilize the on/off operation, even when demand is relatively low. Times when $\mathrm{CO}_{2}$ capture is off are indicated by the sudden increases in coal-based power generation when the system load nears the daily peak load.

2.3.4 FLEX Season: Flexible $\mathrm{CO}_{2}$ Capture Option. $\mathrm{CO}_{2}$ capture is turned off during the entire season between days where electricity demand surpasses a threshold value. This season starts the day prior to the first day a threshold load is exceeded and ends after the last day the system load is above the specified level. The model defines this threshold value based on a grid reserve margin specification. Because the reserve margin is calculated from a single peak load value, a reserve margin specification can be reinterpreted as a threshold load above which $\mathrm{CO}_{2}$ capture must be turned off. FLEX Season represents an extreme case where once $\mathrm{CO}_{2}$ capture is turned off, difficulty bringing the system back online within a short time frame dictates that it will not be returned to full-load $\mathrm{CO}_{2}$ capture operation until the peak load season is over. An illustration of this strategy is shown in Fig. 5, which plots the daily ERCOT peak load throughout 2006, along with a potential $\mathrm{CO}_{2}$ capture "off season."

2.3.5 FLEX Hours: Flexible $\mathrm{CO}_{2}$ Capture Option. $\mathrm{CO}_{2}$ capture is turned off only during specific hours when electricity demand exceeds the designated threshold value or reserve margin. This case represents the opposite end of the system response time continuum where $\mathrm{CO}_{2}$ capture can be turned on and off within an hour. Figure 6 demonstrates how this scenario would distribute generation on August 17, 2006, the highest peak load day of 2006.

\subsection{Base Case Model Inputs}

2.4.1 Reserve Margin. The base case reserve margin is specified at $18.3 \%$. This value is chosen because it corresponds to the requirement to fully replace all capacity lost to $\mathrm{CO}_{2}$ capture. While the ERCOT minimum reserve margin is $12.5 \%$, using $18.3 \%$ allows this study to be compared with those that assume that replacement capacity is required when $\mathrm{CO}_{2}$ capture is installed. As a result, the new net capacity required in CCS Base with base case inputs will be equivalent to the power required to operate $\mathrm{CO}_{2}$ capture on the entire ERCOT coal fleet.

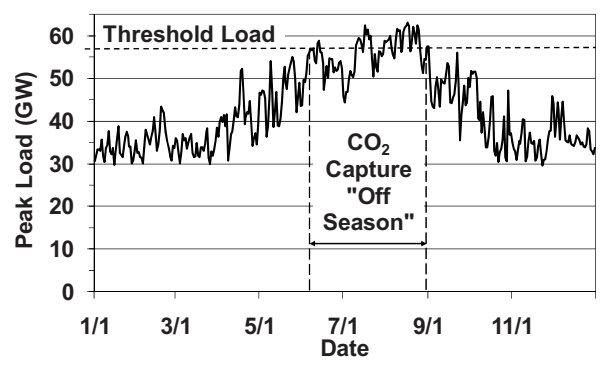

Fig. 5 The seasonal variation in ERCOT daily peak load in 2006 causes a $\mathrm{CO}_{2}$ capture off season for FLEX Season

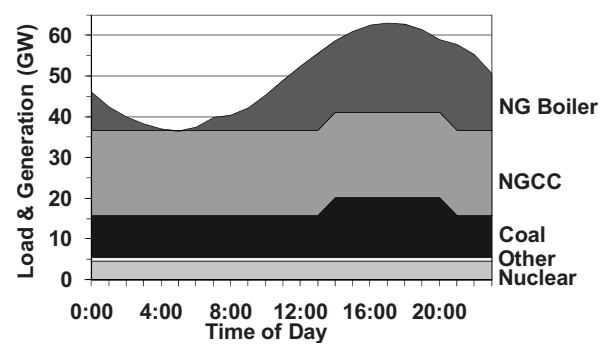

Fig. 6 The FLEX Hours load and generation on August 17, 2006 (the maximum peak load day in 2006) has a $\mathrm{CO}_{2}$ capture off period when load exceeds the threshold load

2.4.2 $\mathrm{CO}_{2}$ Capture System. As stated above, the model assumes that the MEA CO 2 capture system removes $90 \%$ of the $\mathrm{CO}_{2}$ from the coal-based power plant flue gas. Estimates for capture energy requirement vary widely in the literature, but this study assumes that $\mathrm{CO}_{2}$ capture and compression require $30 \%$ of plant output, a value representative of those presented in recent work.

2.4.3 $\mathrm{CO}_{2}$ Emissions Rates. Emissions rates are expressed in metric tons of $\mathrm{CO}_{2}$ per megawatt-hour $\left(\mathrm{tCO}_{2} / \mathrm{MWh}\right)$. These values are determined using weighted average $\mathrm{CO}_{2}$ emission rates for ERCOT plants of each generation type. $\mathrm{CO}_{2}$ emission rates are calculated using 2004 data, but because the fossil fuel-based power generation in ERCOT did not change significantly from 2004 to 2006, calculated values are assumed to be reasonably accurate. Because this analysis only considers point-of-use emissions, nuclear power and all sources accounted for in the "other" generation are assumed to have negligible $\mathrm{CO}_{2}$ emissions.

2.4.4 Electricity Production Costs. All cost values in this study are normalized to 2006 dollars. In this study, electricity production costs include fuel costs and other operating and maintenance $(\mathrm{O} \& \mathrm{M})$ costs, but they do not contain capital charges. While capital charges are important in a single plant analysis that investigates lifetime plant costs in order to make investment decisions, the marginal costs of generating electricity are most important to electric grid operation, because these costs are used to make dispatch decisions. As an approximation, marginal costs are constant throughout the output range of each plant type.

For natural gas-fired plants and coal-fired generating facilities without $\mathrm{CO}_{2}$ capture, marginal generation costs are determined using published nonfuel O\&M costs, 2006 average coal and natural gas prices in Texas, and a weighted average heat rate in the ERCOT grid for each plant type. Fuel prices, particularly natural gas, have been volatile in the recent years, but 2006 fuel prices are used to maintain consistency and for comparison purposes. The average heat rate is calculated using 2004 data, but this methodology is again assumed to yield a reasonably accurate result. Marginal costs for nuclear power are specified directly from literature and do not use a specified heat rate or fuel cost. As indicated above, "other" generation uses the marginal cost for wind power.

The marginal generation cost for coal-based generation with $\mathrm{CO}_{2}$ capture using MEA absorption was determined using the cost of electricity (COE) for a subcritical pulverized coal-based power plant retrofitted with both a MEA and flue gas desulfurization (FGD) system, reported as 70.40 USD/MWh by Rao and Rubin 2002 (2000 dollars) [5]. Because MEA is more prone to degradation if exposed to $\mathrm{SO}_{2}$ in flue gas, Rao and Rubin found that a retrofit MEA+FGD will have a lower COE than a MEA retrofit alone, despite higher capital costs. If all ERCOT coal-based plants were retrofitted, several would require $\mathrm{SO}_{2}$ controls for the efficient use of an MEA-based system. Because the COE reported in Ref. 5 includes capital charges, marginal costs are estimated using another article from the same authors that estimates a $36 \%$ contribution of capital charges to the $\mathrm{COE}$ for an amine-based $\mathrm{CO}_{2}$ capture system [12]. Capital cost of the FGD system is assumed to 
Table 1 MEA system parameters and 2006 average fuel costs in Texas are used as model inputs $[15,16]$

\begin{tabular}{lc}
\hline \hline Parameters & $(\%)$ \\
\hline $\mathrm{CO}_{2}$ capture system energy penalty & $30 \%$ \\
$\mathrm{CO}_{2}$ capture efficiency & $90 \%$ \\
& (USD/MMBTU) \\
Coal cost & 1.48 \\
Natural Gas cost & 6.60 \\
\hline \hline
\end{tabular}

Table 2 Heat rates, marginal generation costs, and $\mathrm{CO}_{2}$ emission rates are used as model inputs $[5,12,15,17-19]$

\begin{tabular}{lccc}
\hline \hline $\begin{array}{l}\text { Generation } \\
\text { source }\end{array}$ & $\begin{array}{c}\text { Fossil fuel heat rate } \\
\text { (MMBtu/MWh) }\end{array}$ & $\begin{array}{c}\text { Generation cost } \\
\text { (USD/MWh) }\end{array}$ & $\begin{array}{c}\mathrm{CO}_{2} \text { emissions rate } \\
\left(\mathrm{tCO}_{2} / \mathrm{MWh}\right)\end{array}$ \\
\hline Coal & 11.0 & 21.68 & 1.04 \\
Coal+CCS & $\mathrm{n} / \mathrm{a}^{\mathrm{a}}$ & 52.75 & 0.15 \\
NGCC & 8.98 & 64.45 & 0.48 \\
NG boiler & 11.8 & 83.14 & 0.63 \\
NGGT & 13.1 & 91.83 & 0.69 \\
Nuclear & $\mathrm{n} / \mathrm{a}$ & 17.15 & 0 \\
Other & $\mathrm{n} / \mathrm{a}$ & 10.52 & 0 \\
\hline
\end{tabular}

${ }^{\mathrm{a}}$ Heat rate is not included in the estimate of generation costs for coal facilities with $\mathrm{CO}_{2}$ capture. See 2.4.4 for methodology regarding Coal+CCS capture generation costs.

${ }^{\mathrm{b}}$ As stated in 2.4 .4 , nuclear costs are specified directly rather than using a fuel cost and heat rate.

be a much higher percentage of its contribution to COE, so it is assumed that taking 64\% of the full 70.40 USD (2000 dollars) $\mathrm{COE}$ is a conservative estimate of the marginal costs of coal-fired generation using $\mathrm{CO}_{2}$ capture.

Tables 1 and 2 summarize important model assumptions.

\section{Results and Discussion}

3.1 Model Validation. Table 3 summarizes the comparison of model results for $B A U$ with actual data from 2006 . While ERCOT reports $305 \times 10^{6} \mathrm{MWh}$ of total generation in 2006, the value used for model validation is the sum of the actual ERCOT demand in every hour of 2006 . This value of $311 \times 10^{6} \mathrm{MWh}$ does not represent a continuous demand variation, but it is more consistent with the model, which calculates generation at hourly intervals. Because $\mathrm{CO}_{2}$ emissions in ERCOT in 2006 are not available, the model calculation is compared with 2004 emissions. This comparison is reasonable because the total ERCOT generation in 2004, differs from the 2006 generation by less than $2 \%$.

The total generation does not change because the model requires that the actual ERCOT demand is always met. Because the model does not account for varying availability of coal-fired

Table 3 Calculated and actual generation and $\mathrm{CO}_{2}$ emissions for each plant type are compared for model validation $[9,17,20]$

\begin{tabular}{lccc}
\hline \hline $\begin{array}{l}\text { Generation } \\
\text { source }\end{array}$ & $\begin{array}{c}\text { Model } \\
\text { calculation }\end{array}$ & $\begin{array}{c}\text { Actual } \\
\text { data }\end{array}$ & $\begin{array}{c}\% \\
\text { difference }\end{array}$ \\
\hline Coal & 2006 Generation & (million MWh) & \\
Natural gas & 129 & 116 & +11 \\
Nuclear & 133 & 144 & -7.7 \\
Other & 40 & 42 & -5 \\
Total & 8.8 & 8.7 & +1.1 \\
& 311 & 311 & 0 \\
Coal & $2006 \mathrm{CO}_{2}$ & Emissions (Mt) & \\
Natural gas & 133 & 121 & +10 \\
Total & 66 & 73 & -10 \\
\hline \hline
\end{tabular}

Journal of Energy Resources Technology

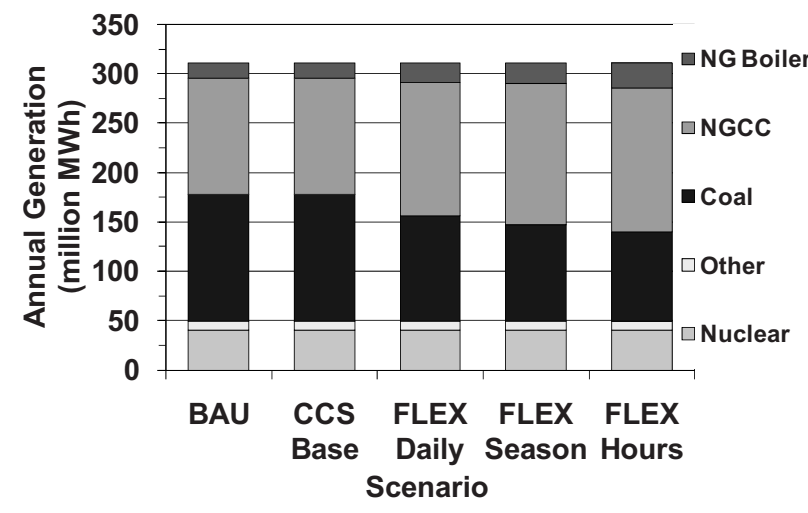

Fig. 7 Annual generation by plant type is compared between scenarios, showing relative changes in coal- and natural gasbased electricity generation

plants, coal-based power generation is calculated $11 \%$ higher than the actual value, causing a corresponding $8 \%$ underestimate of natural gas-fired generation. This effect produces estimates for coal- and natural gas-based emissions that are respectively higher and lower than the actual quantities, with the net effect being a slight overestimate of total $\mathrm{CO}_{2}$ emissions. Despite these offsets, calculated values for this first-order model compare well with observed quantities.

3.2 Scenario Comparison. Figure 7 displays the calculated generation mix for each of the five scenarios. The lowest cost nuclear and "other" generation are constant for all scenarios. Because the model does not account for variations in plant availability and specific plant performance constraints, ample NGCC and NG boiler capacity prevent the use of any NGGT units. Since replacement capacity in CCS Base is coal-fired generation with $\mathrm{CO}_{2}$ capture, coal-based generation does not change relative to $B A U$; thus, the entire generation mix remains the same. Among flexible $\mathrm{CO}_{2}$ capture scenarios, FLEX Daily uses the most coalfired electricity generation, followed by FLEX Season and FLEX Hours, which simply reflects the order of most to least time $\mathrm{CO}_{2}$ capture is turned off.

Figure 8 displays the percent of hours throughout the year when $\mathrm{CO}_{2}$ capture is on at full-load for each scenario. There are very few hours when $\mathrm{CO}_{2}$ capture must be turned off based on the specified base case reserve margin, so FLEX Hours operates $\mathrm{CO}_{2}$ capture for $99 \%$ of the year. Utilization of $\mathrm{CO}_{2}$ capture is nearly the same between CCS Base and FLEX Hours; the major difference between these cases is that CCS Base requires new replacement capacity, while FLEX Hours utilizes existing natural gasfired facilities when $\mathrm{CO}_{2}$ capture is on. Off time in FLEX Hours amounts to just $99 \mathrm{~h}$ in 2006 between June 12 and August 25. Hence, the total off season for FLEX Season is June 11 through

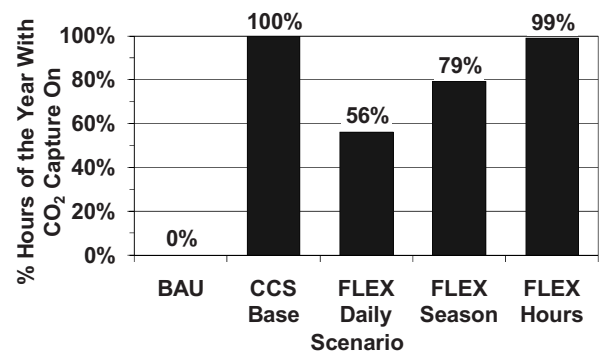

Fig. 8 The percent of hours in 2006 that $\mathrm{CO}_{2}$ capture is turned on is compared between scenarios, showing the difference between always on $\mathrm{CO}_{2}$ capture ( $C C S$ Base) and the flexible $\mathrm{CO}_{2}$ capture scenarios (FLEX Daily/Season/Hours) 


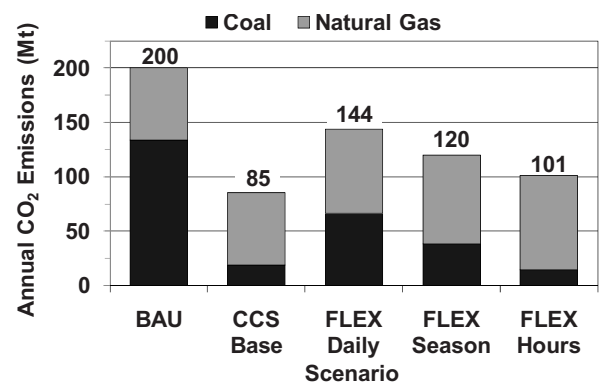

Fig. 9 Annual $\mathrm{CO}_{2}$ emissions are compared between scenarios, showing relative changes in coal- and natural gasbased $\mathrm{CO}_{2}$ emissions

August 26, which accounts for $21 \%$ of the year. FLEX Daily, which uses the on/off operation for peak loads everyday, runs $\mathrm{CO}_{2}$ capture at full-load for $56 \%$ of the year.

As shown in Fig. 9, from a base level of approximately 200 $\mathrm{MtCO}_{2}, \mathrm{CCS}$ Base has the greatest $\mathrm{CO}_{2}$ emissions reduction at $57 \%$ because of its greater use of $\mathrm{CO}_{2}$ capture at coal-fired facilities. Despite the use of the on/off operation in flexible $\mathrm{CO}_{2}$ capture scenarios, the system-wide reduction in $\mathrm{CO}_{2}$ emissions is dramatic. Even FLEX Daily reduces emissions by $28 \%$. Despite a 76 day "off season," FLEX Season reduces emissions by $40 \%$, and FLEX Hours reduces $\mathrm{CO}_{2}$ emissions by $50 \%$. Though capture systems remove $90 \%$ of the $\mathrm{CO}_{2}$ from coal-fired plant flue gas during full-load $\mathrm{CO}_{2}$ capture, some of this $\mathrm{CO}_{2}$ reduction is offset in on/off scenarios by emissions from natural gas-fired plants that operate to replace the base load capacity lost to the energy requirement of $\mathrm{CO}_{2}$ capture. However, these natural gas-fired plants emit $\mathrm{CO}_{2}$ at a much lower rate per MWh of electricity, as shown in Table 2. Even in the extreme case of turning $\mathrm{CO}_{2}$ capture off nearly half of the year, significant $\mathrm{CO}_{2}$ emissions reductions are still achieved. Because FLEX Season and FLEX Hours represent maximum and minimum response time of a dynamic $\mathrm{CO}_{2}$ capture plant, these scenarios indicate the bounds of the $\mathrm{CO}_{2}$ emissions reduction that may be achieved with full penetration of flexible $\mathrm{CO}_{2}$ capture into the ERCOT grid under the specified model assumptions.

Using calculated generation data and the marginal generation costs described above, the model determines a system-wide average generation cost and cost per ton of $\mathrm{CO}_{2}$ avoided. Average generation cost for $B A U$ is approximately $40 \mathrm{USD} / \mathrm{MWh}$, and FLEX Hours has the highest cost at 55 USD/MWh, a $37 \%$ increase. Generation costs for on/off scenarios follow a predictable pattern based on model assumptions; the more often $\mathrm{CO}_{2}$ capture is used, the more expensive electricity production will be. However, this result is not entirely due to the cost of generation with $\mathrm{CO}_{2}$ capture; rather, another reason for the cost increase is the greater use of natural gas-based generation for base load when $\mathrm{CO}_{2}$ capture operates at full-load. High natural gas fuel costs relative to coal are thus a major reason for any increase in average generation costs. Because the marginal cost at coal-fired facilities with $\mathrm{CO}_{2}$ capture is less than that of natural gas-fired generation, CCS Base has a lower average generation cost than FLEX Hours at $53 \mathrm{USD} / \mathrm{MWh}$.

The system average cost per ton of $\mathrm{CO}_{2}$ avoided is 34.91 $\mathrm{USD} / \mathrm{tCO}_{2}$ for CCS Base and ranges between 45.44-46.39 $\mathrm{USD} / \mathrm{tCO}_{2}$ for flexible $\mathrm{CO}_{2}$ capture scenarios. CCS Base has a lower $\mathrm{CO}_{2}$ avoidance cost due to a larger $\mathrm{CO}_{2}$ emissions reduction at a lower average generation cost. This result indicates that based on generation costs alone, $\mathrm{CO}_{2}$ emissions can be reduced more economically by operating $\mathrm{CO}_{2}$ capture continuously rather than using flexible $\mathrm{CO}_{2}$ capture along with additional natural gas-fired generation when $\mathrm{CO}_{2}$ capture is on. However, if natural gas-fired units were to be used as replacement capacity in CCS Base instead

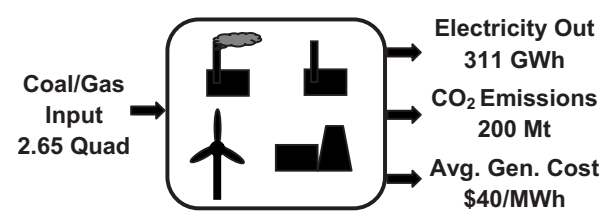

Fig. $10 B A U$ resource flows include annual fuel input, electricity and $\mathrm{CO}_{2}$ output, and system-wide average generation cost

of coal-fired plants with $\mathrm{CO}_{2}$ capture, calculated generation, $\mathrm{CO}_{2}$ emissions, and cost values would be near those of FLEX Hours. While CCS Base is more attractive on a USD/tCO 2 avoided basis, this result comes at the large expense of building new power plants, whose capital costs are not included in model calculations. CCS Base, which assumes replacement of all capacity lost to $\mathrm{CO}_{2}$ capture, requires over $4400 \mathrm{MW}$ of new installed capacity (approximately four new large-scale power plants). If a new subcritical coal-fired plant with $\mathrm{CO}_{2}$ capture costs $2900 \mathrm{USD} / \mathrm{kW}$, the on/off operation provides savings of 12.8 billion USD [13]. Furthermore, the amount of time $\mathrm{CO}_{2}$ capture must be turned off is a very small percentage of the year, so utilization of capitally intense $\mathrm{CO}_{2}$ capture systems is still high. For comparison purposes, if replacement capacity is instead NGCC at $550 \mathrm{USD} / \mathrm{kW}$ or a subcritical coal-based facility without $\mathrm{CO}_{2}$ capture at 1550 USD/ $\mathrm{kW}$, capital cost savings would be 2.44 and 6.84 billion USD, respectively [13].

3.3 Comparison of Resource Flows: $B A U$ and FLEX Hours. Another way to compare scenarios is to consider resource flows in the system. Primary resource flows for BAU and FLEX Hours are shown in Figs. 10 and 11 to compare the current ERCOT grid with the best case scenario for $\mathrm{CO}_{2}$ emissions reduction without a new capacity requirement. These figures demonstrate that another effect of implementing $\mathrm{CO}_{2}$ capture is increased fuel use for additional natural gas-based electricity generation during full-load $\mathrm{CO}_{2}$ capture. This increased fuel use reduces the overall electric grid efficiency of fossil fuel use, defined as fossil-based electricity output per coal and natural gas input, which is $34 \%$ for $B A U$ and $30 \%$ for FLEX Hours. CCS Base, which uses far more coal-fired generation with $\mathrm{CO}_{2}$ capture than all flexible scenarios, has the lowest grid efficiency at $27 \%$.

Tables 4 and 5 show the base case results from all five scenarios.

3.4 Sensitivity to Reserve Margin. Because the reserve margin specification effectively sets the load threshold above which new capacity must be installed or $\mathrm{CO}_{2}$ capture must be turned off, it has a strong impact on how a system with $\mathrm{CO}_{2}$ capture must be planned and operated. Using the same 2006 ERCOT load and initial installed capacity data, CCS Base is modeled for various reserve margin specifications, and Fig. 12 shows the amount of new capacity that must be installed. Because reserve margin is determined by the single highest demand of the year, this capacity requirement varies linearly with the reserve margin. The intersection of this plot with the horizontal dotted line represents the base case CCS Base described above, where all capacity lost to $\mathrm{CO}_{2}$ capture must be replaced. The actual $12.5 \%$ ERCOT minimum

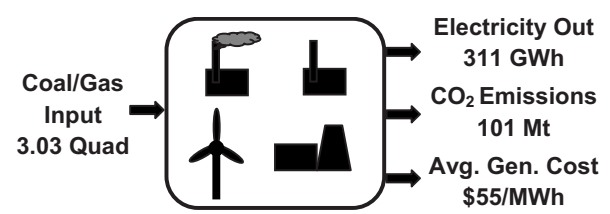

Fig. 11 FLEX Hours resource flows include annual fuel input, electricity and $\mathrm{CO}_{2}$ output, and system-wide average generation cost 
Table 4 Summary of generation by source and the number of $\mathrm{CO}_{2}$ capture "off hours" for each scenario

\begin{tabular}{|c|c|c|c|c|c|c|c|}
\hline Scenario & $\begin{array}{l}\text { Coal generation } \\
\text { (million MWh) }\end{array}$ & $\begin{array}{l}\text { NGCC generation } \\
\text { (million MWh) }\end{array}$ & $\begin{array}{l}\text { NG boiler generation } \\
\quad(\text { million } \mathrm{MWh})\end{array}$ & $\begin{array}{l}\text { Nuclear generation } \\
\text { (million MWh) }\end{array}$ & $\begin{array}{l}\text { Other generation } \\
\text { (million } \mathrm{MWh})\end{array}$ & $\begin{array}{l}\text { Total generation } \\
\text { (million MWh) }\end{array}$ & $\begin{array}{c}\text { No. of hours } \\
\text { with } \mathrm{CO}_{2} \\
\text { capture off }\end{array}$ \\
\hline$B A U$ & 129 & 118 & 15 & 40.3 & 8.81 & 311 & $8758^{\mathrm{a}}$ \\
\hline CCS Base & 129 & 118 & 15 & 40.3 & 8.81 & 311 & 0 \\
\hline FLEX Daily & 107 & 135 & 20 & 40.3 & 8.81 & 311 & 3845 \\
\hline FLEX Season & 98 & 143 & 21 & 40.3 & 8.81 & 311 & 1824 \\
\hline FLEX Hours & 91 & 146 & 26 & 40.3 & 8.81 & 311 & 99 \\
\hline
\end{tabular}

${ }^{\mathrm{a}}$ Data set contains 8758 points rather than the full 8760 hours in a year

reserve margin requires only $220 \mathrm{MW}$ of new capacity, but new required capacity increases substantially if future planning indicates that a more stringent value should be used to maintain grid reliability. No new capacity is required below a reserve margin of $12.2 \%$. Requiring only $220 \mathrm{MW}$ with a $12.5 \%$ reserve margin suggests that the actual 2006 ERCOT grid could manage a large amount of $\mathrm{CO}_{2}$ capture retrofitting without new capacity, regardless of flexible $\mathrm{CO}_{2}$ capture. However, because increasing electricity demand indicates that ERCOT may fail to achieve a minimum $12.5 \%$ reserve margin within a few years, it appears beneficial for flexible $\mathrm{CO}_{2}$ capture to mitigate any additional strain on system capacity [14].

The reserve margin specification also has a strong effect on the on/off operation, as Fig. 13 displays. Increasing the reserve margin increases the chances that FLEX Season will find an atypically high demand away from the highest annual peaks. Consequently, there is a rapid increase in the amount of time $\mathrm{CO}_{2}$ capture is turned off that approaches $23 \%$ of the year at a $20 \%$ reserve margin. FLEX Hours has a much smaller increase in off hours as the reserve margin increases because there are still very few hours throughout the year when the system load nears installed capacity. A plot of off hours versus specified reserve margin for a flexible $\mathrm{CO}_{2}$ capture system with an intermediate system response time would presumably lie between those of FLEX Season and FLEX Hours.

The analysis above assumes that flexible $\mathrm{CO}_{2}$ capture systems are required to turn off when the specified reserve margin is breached. However, if ERCOT considers the energy being used for $\mathrm{CO}_{2}$ capture to be "available" even during full-load $\mathrm{CO}_{2}$ capture, the $\mathrm{CO}_{2}$ capture system may not have to turn off unless a reliability event such as a plant failure occurs. Thus, simply having the ability to operate flexibly may be enough to avoid having to build replacement capacity.

These results indicate that in order for generators using flexible $\mathrm{CO}_{2}$ capture to effectively plan when capture systems are on or off, it will be essential to clearly define and communicate the reserve margin specification and the availability of the energy being used for $\mathrm{CO}_{2}$ capture.

\section{Conclusions}

A grid-level model was created in MATLAB and used to study the implications and tradeoffs of installing flexible $\mathrm{CO}_{2}$ capture systems on all coal-based power plants in the 2006 ERCOT electric grid. Under base case model assumptions, the ability to turn $\mathrm{CO}_{2}$ capture on and off in response to electric grid demand prevents the need for over $4400 \mathrm{MW}$ of new capacity, saving approximately 12.8 billion USD in capital costs. Because the highest system loads are very infrequent, on/off capable $\mathrm{CO}_{2}$ capture systems with a response time of $1 \mathrm{~h}$ or less must be off for only 99 nonconsecutive hours of the year to avoid new capacity requirements. If long response times require systems that are turned off to remain so for the entire peak load season, the total "capture off" season is 76 days between June 11 and August 26. Despite the time off, these scenarios achieve $50 \%$ and $40 \%$ system-wide $\mathrm{CO}_{2}$ emissions reduction, comparable to the $57 \%$ reduction with continuous full-load $\mathrm{CO}_{2}$ throughout the year. These two on/off scenarios bound the range of possible system response time, so an ERCOT grid with widespread implementation of flexible $\mathrm{CO}_{2}$ capture may be expected to have $\mathrm{CO}_{2}$ emissions reduction within this range.

System average generation costs do not change significantly from the use of on/off $\mathrm{CO}_{2}$ capture. However, the always on scenario has lower $\mathrm{CO}_{2}$ avoidance costs because it assumes that any required replacement capacity consists of coal-based generation with $\mathrm{CO}_{2}$ capture, which has lower emissions and lower marginal generation costs than natural gas-based generation with assumed fuel prices. At lower natural gas prices, gas-fired facilities might be used before coal-based generation with $\mathrm{CO}_{2}$ capture to meet the base load. In all on/off $\mathrm{CO}_{2}$ capture scenarios, running $\mathrm{CO}_{2}$ capture requires the increased use of natural gas-fired plants for base load generation, so natural gas fuel prices are the primary determinant of cost variations among scenarios using flexible $\mathrm{CO}_{2}$ capture.

Electric grid reserve margin specification is important for determining the threshold load above which $\mathrm{CO}_{2}$ capture must be turned off, so clearly defining this value for plant operators will be essential to ensure proper planning and implementation of flexible $\mathrm{CO}_{2}$ capture. If the energy used for $\mathrm{CO}_{2}$ capture is still considered available by the grid operator, simply having the ability to operate $\mathrm{CO}_{2}$ capture flexibly may be enough to prevent the need for new replacement capacity.

\section{Future Work}

While this study addresses some key concerns with using on/off $\mathrm{CO}_{2}$ capture to eliminate the need for replacement capacity, future

Table 5 Summary of fuel use, electric grid efficiency, $\mathrm{CO}_{2}$ emissions, and costs for each scenario

\begin{tabular}{|c|c|c|c|c|c|c|c|c|}
\hline Scenario & $\begin{array}{l}\text { Coal input } \\
\text { (Quad) }\end{array}$ & $\begin{array}{l}\text { Natural gas input } \\
\text { (Quad) }\end{array}$ & $\begin{array}{l}\text { Electric grid } \\
\text { efficiency } \\
(\%)\end{array}$ & $\begin{array}{l}\mathrm{CO}_{2} \text { from } \\
\text { coal } \\
(\mathrm{Mt})\end{array}$ & $\begin{array}{l}\mathrm{CO}_{2} \text { from } \\
\text { natural gas } \\
\quad(\mathrm{Mt})\end{array}$ & $\begin{array}{c}\text { Total } \mathrm{CO}_{2} \\
\text { Emissions }(\mathrm{Mt}) \\
(\% \text { reduction })\end{array}$ & $\begin{array}{c}\text { Average generation cost } \\
\text { (USD/MWh; } \\
\% \text { increase) }\end{array}$ & $\begin{array}{c}\text { Cost of } \mathrm{CO}_{2} \\
\text { avoidance } \\
\text { (USD/t) }\end{array}$ \\
\hline$B A U$ & 1.42 & 1.24 & 33.7 & 134 & 66.1 & 200 & 39.98 & $\mathrm{n} / \mathrm{a}$ \\
\hline CCS Base & 2.03 & 1.24 & 27.4 & 19.1 & 66.1 & $85.2[-57.4]$ & $52.86[+32.2]$ & 34.91 \\
\hline FLEX Daily & 1.42 & 1.44 & 31.2 & 66.3 & 77.3 & $144[-28.2]$ & $48.31[+20.8]$ & 45.92 \\
\hline FLEX Season & 1.42 & 1.53 & 30.3 & 38.5 & 81.6 & $120[-39.9]$ & $51.65[+29.2]$ & 45.44 \\
\hline FLEX Hours & 1.42 & 1.61 & 29.5 & 14.8 & 86.1 & $101[-49.6]$ & $54.78[+37.0]$ & 46.39 \\
\hline
\end{tabular}




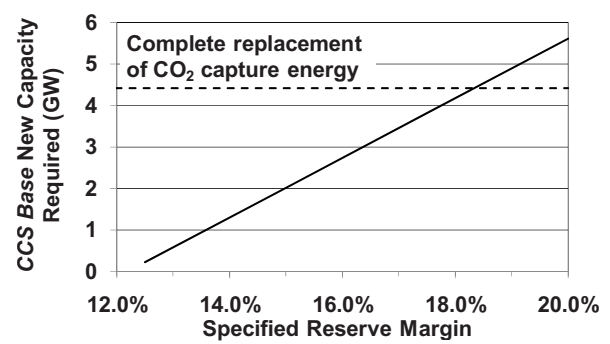

Fig. 12 There is a linear increase of the new capacity required in CCS Base with specified reserve margin, and the horizontal line represents the base case where all capacity lost to $\mathrm{CO}_{2}$ capture is replaced

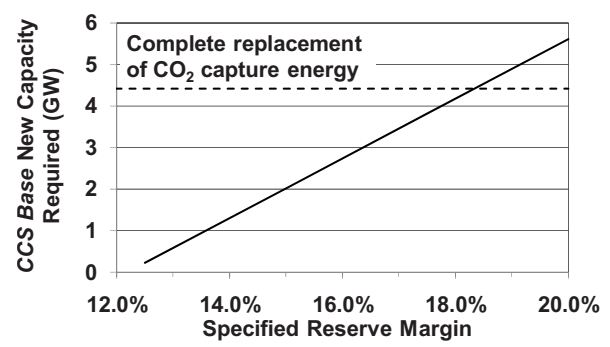

Fig. 13 The number of hours in a year that $\mathrm{CO}_{2}$ capture is turned off increases the specified reserve margin for FLEX Season and FLEX Hours, which bound the range of system response time

model development will allow more detailed sensitivity analyses of parameters such as system response time, $\mathrm{CO}_{2}$ capture energy requirement, and piecewise penetration of $\mathrm{CO}_{2}$ capture into the electric grid. Examining different options for flexible $\mathrm{CO}_{2}$ capture may also be useful to better understand the important tradeoffs between dynamically operating $\mathrm{CO}_{2}$ capture systems. Incorporating actual plant availability, which varies throughout the year from effects such as maintenance schedules and variations in ambient air temperature, may also improve an understanding of how on/off $\mathrm{CO}_{2}$ capture can be utilized to ensure grid reliability while minimizing costs. Ultimately, a rigorous grid model incorporating individual plant specifications and transmission considerations will be necessary to fully understand the implications of flexible $\mathrm{CO}_{2}$ capture in the electric grid.

Another potential opportunity to improve the economics of $\mathrm{CO}_{2}$ capture with flexible operation is by turning capture systems off during daily periods of high electricity price. Selling higher value electricity with the $\mathrm{CO}_{2}$ capture turned off may improve generator profits relative to an operator that runs $\mathrm{CO}_{2}$ capture continuously throughout the year. Future studies will investigate this concept in order to better understand the tradeoffs between the value of electricity and the cost of $\mathrm{CO}_{2}$ emissions in a carbon dioxide constrained electric grid with flexible $\mathrm{CO}_{2}$ capture. It will be important to understand how the value of $\mathrm{CO}_{2}$ may affect electricity prices and grid dispatch decisions when flexible $\mathrm{CO}_{2}$ capture is considered.

\section{Acknowledgment}

This study was prepared with the support of the Luminant Carbon Management Program, along with the Center for International Energy and Environmental Policy, the Cockrell School of Engineering, and the Departments of Mechanical and Chemical Engineering at the University of Texas at Austin. The research has also been funded in part by the United States Environmental Protection Agency (EPA) under the Science to Achieve Results (STAR) Fellowship Program. However, any opinions, findings, conclusions, or recommendations expressed herein are those of the authors alone and do not reflect the views of the sponsors.

\section{References}

[1] Metz, B., Davidson, O., de Coninck, H., Loos, M., and Meyer, L., 2005, IPCC Special Report on Carbon Dioxide Capture and Storage, Cambridge University Press, New York.

[2] USEIA, 2007, "World Carbon Dioxide Emissions From the Use of Fossil Fuels," International Energy Annual 2005, http://www.eia.doe.gov/emeu/iea/ carbon.html

[3] Davidson, R. M., 2007, "Post-Combustion Carbon Capture From Coal Fired Plants-Solvent Scrubbing," Technical Report No. CCC/125, IEA Clean Coal Centre.

[4] Bergerson, J. A., and Lave, L. B., 2007, "Baseload Coal Investment Decisions Under Uncertain Carbon Legislation," Environ. Sci. Technol., 41(10), pp. $3431-3436$.

[5] Rao, A. B., and Rubin, E. S., 2002, “A Technical, Economic, and Environmental Assessment of Amine-Based $\mathrm{CO}_{2}$ Capture Technology for Power Plant Greenhouse Gas Control," Environ. Sci. Technol., 36(20), pp. 4467-4475.

[6] Katzer, J., Ansolabehere, S., Beer, J., Deutch, J., Ellerman, A. D., Friedmann, S. J., Herzog, H., Jacoby, H. D., Joskow, P. L., McRae, G., Lester, R., Moniz, E. J., and Steinfeld, E., 2007, The Future of Coal: Options for a Carbon Constrained World, Massachusetts Institute of Technology, Cambridge, MA.

[7] Chalmers, H., Chen, C., Lucquiaud, M., Gibbins, J., and Strbac, G., 2006 "Initial Evaluation of Carbon Capture Plant Flexibility," Proceedings of the Eight International Conference on Greenhouse Gas Technologies, Elsevier, Oxford, UK.

[8] Gibbins, J. R., Crane, R. I., Lambropoulos, D., Booth, C., Roberts, C. A., and Lord, M., 2005, "Maximizing the Effectiveness of Post Combustion $\mathrm{CO}_{2}$ Capture Systems," Proceedings of the Seventh International Conference on Greenhouse Gas Technologies, Elsevier, Oxford, UK.

[9] ERCOT, 2006, 2006 Annual Report, ERCOT, Taylor, TX.

[10] Jones, S., 2006, Electric Reliability and Resource Adequacy Update, ERCOT, Taylor, TX.

[11] Rubin, E. S., Chen, C., and Rao, A. B., 2007, "Cost and Performance of Fossil Fuel Power Plants With $\mathrm{CO}_{2}$ Capture and Storage," Energy Policy, 35, pp. 4444-4454.

[12] Rao, A. B., and Rubin, E. S., 2006, "Identifying Cost-Effective $\mathrm{CO}_{2}$ Control Levels for Amine-Based $\mathrm{CO}_{2}$ Capture Systems," Ind. Eng. Chem. Res., 45(8), pp. 2421-2429.

[13] USNETL, 2007, "Cost and Performance Baseline for Fossil Energy Plants," Technical Report No. DOE/NETL-2007/1281.

[14] ERCOT, 2007, Report on the Capacity, Demand, and Reserves in the ERCOT Region: Summer Assessment Update, ERCOT, Taylor, TX.

[15] USEIA, 2007, Average Cost of Coal Delivered for Electricity Generation by State, Year-to-Date Through October 2007 and 2006, USDOE, Washington, DC.

[16] USEIA, 2008, Texas Natural Gas Wellhead Price, USDOE, Washington, DC.

[17] USEPA, 2007, Emissions and Generation Resource Integrated Database (eGRID) Ver. 2.1.

[18] 2007, U.S. Electricity Production Costs and Components, NEI, Washington, DC.

[19] IEA and NEA, 2005, Projected Costs of Generating Electricity: 2005 Update, OECD, Paris, France.

[20] ERCOT, 2006, 2006 ERCOT Hourly Load Data, ERCOT, Taylor, TX

[21] Pe-Ltd, 2007, 2006 State of the Market Report for the ERCOT Wholesale Electricity Markets, Potomac Economics, Ltd., Austin, TX. 